\title{
Venlafaxine in the treatment of panic disorder
}

\author{
Martin A Katzman 1,2,3 \\ Leslie Jacobs' \\ 'START Clinic for the Mood and \\ Anxiety Disorders, Toronto, ON, \\ Canada; ${ }^{2}$ University of Toronto, ON, \\ Canada; ${ }^{3}$ Northern Ontario School of \\ Medicine, Toronto, ON, Canada
}

Correspondence: Martin A Katzman START (Stress Trauma, Anxiety, Rehabilitation and Treatment) Clinic for the Mood and Anxiety Disorders, 790 Bay Street-Suite 900, Toronto, ON M5G IN8, Canada

$\mathrm{Tel}+$ I 4165989344

Fax +| 4165988198

Email mkatzman@startclinic.ca

\begin{abstract}
Venlafaxine XR is a novel, dual acting SNRI antidepressant, which inhibits both serotonin and norepinephrine reuptake. Controlled trials have demonstrated the efficacy and safety of venlafaxine in the treatment of panic disorder. Generally well tolerated, with sideeffects that usually abate with continued treatment, venlafaxine is an important option to the SSRIs for the treatment of patients with panic disorder.
\end{abstract}

Keywords: anxiety disorders, panic disorder, antidepressant therapy, remission, venlafaxine, selective serotonin norepinephrine reuptake inhibitor

\section{Introduction}

Anxiety disorders are persistent, cause substantial impairment, and are extremely common, with lifetime prevalence estimates of over $25 \%$ (Kessler et al 1994). As well, it has been reported that the anxiety disorders exert a substantial burden, not only in terms of direct costs of medication and psychotherapy, but also indirect costs associated with impaired functioning in social, educational, and employment aspects of life (Greenberg et al 1999). The annual cost of anxiety disorders in the United States was estimated to be US \$42.3 billion in 1990, and US \$65 billion in 1994 (Greenberg et al 1999; Dupont et al 2002). Unfortunately, anxiety disorders are frequently only treated to a response rate often defined as a $\geq 50 \%$ improvement on the specific disease specific objective rating scale (Ballenger 2001). This can leave patients with substantial morbidity, and in fact, many patients after having what was defined as a "good response" to monotherapy, would still fulfill entry criteria for many trials. Clearly, this is disappointing as it has become quite clear that remission should be the ultimate treatment goal in chronic anxiety disorders (Guidelines for the treatment 2000; Ballenger 2001). Remission in anxiety disorders has been defined as a patient who is symptom free and has a restoration of normal functioning, who is in fact indistinguishable from a person who had never suffered an anxiety disorder (Table 1) (Ballenger 2001).

Panic disorder is characterized by recurrent unexpected panic attacks followed by one month or more of persistent worry about having additional panic attacks (anticipatory anxiety), worry about the implications of the attack, or significant changes in behavior (in relation to the panic attack). In addition, in order for the diagnosis of panic disorder to be made, the panic attacks cannot be due to the psychological effects of a substance or a medical condition, nor should the triggers for the panic attacks be better accounted for by anxiety episodes occurring in conjunction with other psychiatric disorders such as social phobia, post-traumatic stress disorder or depression (APA 1994).

The criterion for a panic attack according to DSM IV-TR requires 4 of the 13 symptoms. In addition, many sufferers may experience "Limited Symptom Attacks," which are similar to panic attacks but occur with fewer than 4 symptoms. These Limited Symptom Attacks, may still be quite disabling and often appear in combination with 
the more severe four symptom panic attacks (Klerman et al 1991). In addition, because panic attacks are usually followed by the development of anticipatory anxiety (fear of having future panic attacks which often leads to agoraphobia and avoidance), a better estimate of severity may be how much the illness prevents the patient from doing. This is further complicated by the comorbidities that often develop in association with panic disorder (including depression, substance abuse, agoraphobia), as well as the significant social and occupational impairment.

Agoraphobia, which often accompanies panic disorder refers, to a patient's "fear or avoidance of situations from which escape might be difficult or embarrassing or from which help may not be readily available" (APA 1994).

The frequency of attacks is often used as an indicator of the severity of panic disorder, but this may be misleading, as the number of panic attacks or limited symptom attacks may be decreased by avoidance of situations in which one feels anxious, thus providing a false indicator of improved mental health. Thus, as stated by Shear and Maser (1994), the assessment of the severity of panic disorder should not only include panic attack (and limited symptom attack) frequency and severity but also severity of phobic avoidance and interference with level of function. As a result, most recent studies in the treatment of panic disorder have used The Panic Disorder Severity Scale (PDSS) developed by Shear et al (1997), which is a validated instrument to assess all of these specific aspects of panic disorder.

\section{Drug therapy in panic disorder}

Thus the goals of pharmacotherapy are not only to reduce the severity and frequency of panic attacks and limited symptom attacks, but also to decrease the avoidance, fearful anticipation, and cognitive distortions associated with the diagnosis. The effectiveness of several types of medications is clearly established, but there remains no guarantee that a certain medication will work in a specific case. Thus the development of more treatment effective options is imperative. As well, the potential presence of common co-existing conditions as well as the presence of on-board medications must be included in the initial evaluation, because the presence of these comorbid conditions may affect the outcome of treatment of the specific treatment for panic disorder (Lydiard and Brawman-Mintzer 1997).

In terms of outcome for studies, the definition of remission has been widely debated. Most recently, Feighner (1999) proposed the definition given in Table 1.
Inevitably, the question arises as to what is the first-line pharmacotherapeutic treatment for panic disorder. While much evidence has pointed to the use of SSRIs (selective serotonin reuptake inhibitors) as the first choice in treatment, significant research also points to the efficacy of the other antidepressants including the tricyclic/heterocyclic antidepressants (TCAD) and monoamine oxidase inhibitors (MAOI). Nevertheless, these agents are unable to match the SSRIs in relationship to issues of tolerability, safety in overdose, and their broader range of established efficacy in commonly co-occurring conditions. Thus the American Psychiatric Association Practice Guidelines for panic disorder (Pollack 1999) and the Canadian guidelines suggest that SSRIs (Canadian Anxiety Disorders Treatment Guidelines Initiative 2006) remain first-line treatment. Even though evidence clearly supports the role for SSRIs as first-line treatments for panic disorder, the response and remission rates suggest a need for more options in managing panic disorder. Studies examining the effectiveness of the SSRIs in panic disorder are listed in Table 2.

\section{Venlafaxine}

Venlafaxine hydrochloride Effexor $^{\circledR}$; Wyeth-Ayerst Co., PA, USA), a structurally novel phenylethylamine $\left(\mathrm{C}_{17} \mathrm{H}_{27} \mathrm{NO}_{2}\right.$ hydrochloride $)$ antidepressant, was first introduced in 1994 for the treatment of major depression (Muth et al 1986) in its immediate-release form. This medication is now available as an extended-release (XR) formulation (Effexor $^{\circledR}$ XR, Wyeth-Ayerst Co., PA, USA), which is indicated for the treatment of major depressive disorder, generalized anxiety disorder, panic disorder, and social anxiety disorder (social phobia) (Wyeth Laboratories 2003). Venlafaxine itself undergoes extensive metabolism in the liver to N-desmethyl-venlafaxine, N,O didesmethyl-venlafaxine, and a few other minor metabolites, but primarily to O-desmethyl-venlafaxine (ODV), which is equiactive and equipotent to venlafaxine.

Table I Proposed objective remission target in panic disorder (Feighner 1999)

Essentially free of panic attacks, no or mild agoraphobic avoidance

Panic Disorder Or

Panic Disorder Severity Scale (PDSS) $\leq 3$ with no individual item score $>1$ 
Table $\mathbf{2}$ List of studies examining the effectiveness of SSRIs in panic disorder

\begin{tabular}{|c|c|c|}
\hline SSRI & $\begin{array}{l}\text { Daily dosage } \\
\text { range }\end{array}$ & Studies \\
\hline Fluvoxamine & (150-300 mg) & $\begin{array}{l}\text { Black et al (1993) } \\
\text { Hoehn-Saric et al (1993) }\end{array}$ \\
\hline Paroxetine & $(40-60 \mathrm{mg})$ & $\begin{array}{l}\text { Ballenger et al (1998) } \\
\text { Lydiard et al (1998) } \\
\text { Oehrberg et al (1995) }\end{array}$ \\
\hline Sertraline & (50-200 mg) & $\begin{array}{l}\text { Londborg et al (1998) } \\
\text { Pohl et al (1998) } \\
\text { Pollack et al (1998) } \\
\text { Rapaport et al (1998) } \\
\text { Pollack et al (2000) } \\
\text { Rapaport et al (200I) } \\
\text { Pollack et al (2002) }\end{array}$ \\
\hline Citalopram & $(20-40 \mathrm{mg})$ & $\begin{array}{l}\text { Wade et al (1997) } \\
\text { Lepola et al (1998) } \\
\text { Leionen et al (2000) }\end{array}$ \\
\hline Fluoxetine & (10-20 mg) & $\begin{array}{l}\text { Michelson et al (1998) } \\
\text { Michelson et al (1999) } \\
\text { Michelson et al (2001) }\end{array}$ \\
\hline
\end{tabular}

\section{Mechanisms of action}

The mechanism of antidepressant action of venlafaxine in humans is believed to be associated with its potentiation of neurotransmitter activity in the central nervous system (CNS). Venlafaxine and its active metabolite, ODV, are potent inhibitors of neuronal serotonin and norepinephrine reuptake and weak inhibitors of dopamine reuptake (Muth et al 1986; Wyeth Laboratories 2003). This weak interaction with dopamine receptors may have clinical applicability at very high doses (Feighner 1999). Specifically, venlafaxine will inhibit reuptake at the noradrenergic reuptake site in the prefrontal cortex (which takes up both noradrenaline in noradrenergic synapses and dopamine in dopaminergic synapses), which specifically will increase concentration of not only noradrenaline but also dopamine in the prefrontal cortex (Moron et al 2002).

However, venlafaxine does not interact with muscarinic cholinergic, $\mathrm{H}_{1}$-histaminergic, or $\alpha_{1}$-adrenergic receptors in vitro, which are thought to be associated with the various anticholinergic, sedative, and cardiovascular effects seen with some other psychotropic drugs ( Feighner 1999; Wyeth laboratories 2003). It also possesses no monoamine oxidase inhibitory activity (Wyeth Laboratories 2003). Venlafaxine rapidly decreases central beta-adrenergic responsiveness, which is seen only after chronic administration of other antidepressants and may correlate with the onset of clinical activity. It exhibits a dose response, and at higher doses the adrenergic effects of the drug are increased (Feighner 1999).

\section{Pharmacokinetic profile}

Steady-state plasma concentrations of venlafaxine and its active metabolite, ODV, are obtained within 3 days of oral multiple-dose administration and exhibit linear kinetics over the dose range $75-450 \mathrm{mg} /$ day. The mean $\pm \mathrm{SD}$ steady state plasma clearance of venlafaxine and ODV is $1.3 \pm 0.6$ and $0.4 \pm 0.2 \mathrm{~L} / \mathrm{h} / \mathrm{kg}$, respectively; apparent elimination halflife is $5 \pm 2$ and $11 \pm 2$ hours, respectively. The apparent (steady-state) volume of distribution is $7.5 \pm 3.7$ and 5.7 $\pm 1.8 \mathrm{~L} / \mathrm{kg}$, respectively. The degree of plasma protein binding is minimal (27\% and 30\%, respectively) (Wyeth Laboratories 2003).

Approximately $92 \%$ of a single oral dose of venlafaxine is absorbed, with a bioavailability of $45 \%$. The bioavailability of venlafaxine or ODV is not affected by food or time of administration (Wyeth Laboratories 2003). When equal daily doses of venlafaxine are administered, as immediate-release or the extended-release, exposure to both venlafaxine and ODV is similar and the fluctuation in plasma concentrations is slightly lower with the venlafaxine XR capsule. Venlafaxine XR formulation provides a slower rate of absorption, but the same extent of absorption compared with the immediaterelease tablet.

Venlafaxine is metabolized in the liver, primarily by CYP2D6, but any differences between CYP2D6 and extensive metabolizers are not expected to be clinically important (Wyeth Laboratories 2003).

Excretion of venlafaxine and ODV is primarily through the kidneys, and the approximate elimination half-life is 5 hours for venlafaxine and 11 hours for ODV. Within 48 hours, $87 \%$ of a single dose was recovered in the urine as unchanged venlafaxine (5\%), unconjugated ODV (29\%), conjugated ODV (26\%), or other minor inactive metabolites $(27 \%)$. There is no difference in the elimination half-life between venlafaxine and venlafaxine XR (Wyeth Laboratories 2003).

\section{Venlafaxine in panic disorder}

A number of concerns have been raised as to whether there is a role for venlafaxine in the treatment of panic disorder, related to its role in noradrenergic reuptake blockade. Because of its known efficacy in the other anxiety disorders, studies have been initiated with venlafaxine in panic disorder. 
Liebowitz and colleagues (2004) undertook a placebocontrolled, flexible-dose trial of venlafaxine XR in patients suffering from panic disorder with or without agoraphobia. In this trial, 323 subjects meeting study criteria (including baseline CGI-S [Clinical Global Impression-Severity Scale] $\geq 4, \geq 8$ full symptom panic attacks in the 4 -weeks preceding admission to the study and $\geq 4$ full symptom panic attacks in the 17 days preceding entry into the study) were randomly enrolled in a 10-week trial of venlafaxine (flexible dose range 75-225 mg daily) or placebo, with a 2-week taper period. The primary outcome measure was the number of patients who were free from full symptom panic attacks ( $\geq 4$ symptoms) as measured on the PAAS (Panic and Anxiety Anticipatory Scale), at the last and final visit on therapy (FOT) evaluation. Secondary outcome measures included the change in the total PDSS (Panic Disorder Severity Scale), and the response rate as measured on the Clinical Global Impression-Improvement at a score of 1 (very much improved) or 2 (much improved). As well, Liebowitz and colleagues (2004) assessed changes in panic frequency (as measured on the PAAS, Remission Rate (CGI-Severity of 1 and panic free), Phobia Scales (fear and avoidance factors), change from baseline in percentage of time that patients experience anticipatory anxiety, as well as changes reported quality of life (Q-LES-Q; Quality of Life Enjoyment and Satisfaction Questionnaire), and disability (on the SDS; Sheehan Disability Scale). After the 10-week trial, Liebowitz et al (2004) reported that with a mean daily dose ranging from 125.6 to $194.1 \mathrm{mg}$, significant differences were noted in total PDSS change ( $\mathrm{p} \leq 0.05)$ beginning at week 4 , with significantly more venlafaxine XR patients reaching response at week 4 and 10 than those in the placebo group. While not statistically significant, trends towards significance were observed in terms of remission rate $(p=0.067)$, percentage of panic-free patients $(p=0.056)$, and the median change in panic frequency from baseline $(\mathrm{p}=0.058)$. Liebowitz and colleagues (2004) also reported significant reductions in the phobia scale (fear and avoidance factors) but not the percentage of time patients suffered with anticipatory anxiety (see Table 3).

Bradwejn and colleagues (2005) reported on a second 10 -week trial (with a 2-week taper period) of venlafaxine (flexible dose range 75-225 mg daily) or placebo in patients suffering with panic disorder with or without agoraphobia. In this trial, 323 subjects meeting study criteria (including baseline CGI-S [Clinical Global Impression-Severity Scale] $\geq 4, \geq 8$ full symptom panic attacks in the 4 -weeks preceding admission to the study and $\geq 4$ full symptom panic attacks in the 17 days preceding entry into the study) were randomly enrolled in the 10 -week trial of venlafaxine or placebo. The primary outcome measure was the percentage of patients free from full symptom panic attacks ( $\geq 4$ symptoms) as measured on the PAAS (Panic and Anxiety Anticipatory Scale), at the FOT evaluation. Secondary outcome measures included the median change from baseline in the panic attack frequency, as measured on the PAAS, change in the total PDSS (Panic Disorder Severity Scale), and the response rate as measured on the Clinical Global Impression-Improvement at a score of 1 (very much improved) or 2 (much improved), Remission Rate (CGI-Severity of 1 and panic free), Phobia Scales (fear and avoidance factors), change from baseline in percentage of time that patients experience anticipatory anxiety, as well as changes in reported quality of life (Q-LES-Q; Quality of Life Enjoyment and Satisfaction Questionnaire), and disability (on the SDS; Sheehan Disability Scale). After the 10-week trial, Bradwejn et al (2005) reported that a mean daily dose ranging from 115 to $163 \mathrm{mg}$ resulted in significant differences in reduction of panic attack frequency from baseline, compared with the placebo-treated group ( $\mathrm{s} 00.05$ ). Interestingly, while there was a significant difference in percentage of patients who were panic free on venlafaxine XR at weeks 4 and 8 , no difference was found at the FOT evaluation. This may have been related to the difference in baseline panic attacks in the venlafaxine XR treatment group (with a significantly larger baseline rate in panic attacks in the venlafaxine group). However, Bradwejn et al (2005) reported significant differences in response and remission rates ( $\mathrm{p} \leq 0.05)$, with almost $70 \%$ of the patients on venlafaxine XR reaching response as measured on the CGI. As well, significant improvement in the Q-LES-Q and three of the four domains of the SDI was also noted (Table 3 ).

In another short-term trial, Pollack et al (2005) reported on a randomized, placebo-controlled, 12-week, multi-center clinical trial of paroxetine at a dose of $40 \mathrm{mg}$ daily, venlafaxine XR at a dose of $75 \mathrm{mg}$ daily, venlafaxine XR at a dose of 225 $\mathrm{mg}$ daily, and placebo in patients suffering from DSM-IV diagnosed panic disorder with or without agoraphobia. Six hundred and twenty-one subjects completed the trial. The primary outcome measure was the number of subjects free from full symptom panic attacks ( $\leq 4$ symptom panic attacks). Secondary outcome measures included the total PDSS (Panic Disorder Severity Scale), the response rate (endpoint CGI-I of 1 or 2), the remission rate (endpoint CGI-S of 1 or 2 and panic free), change from baseline in panic attack frequency 
Table 3 Double-blind trials evaluating venlafaxine $X R$ in patients with panic disorder

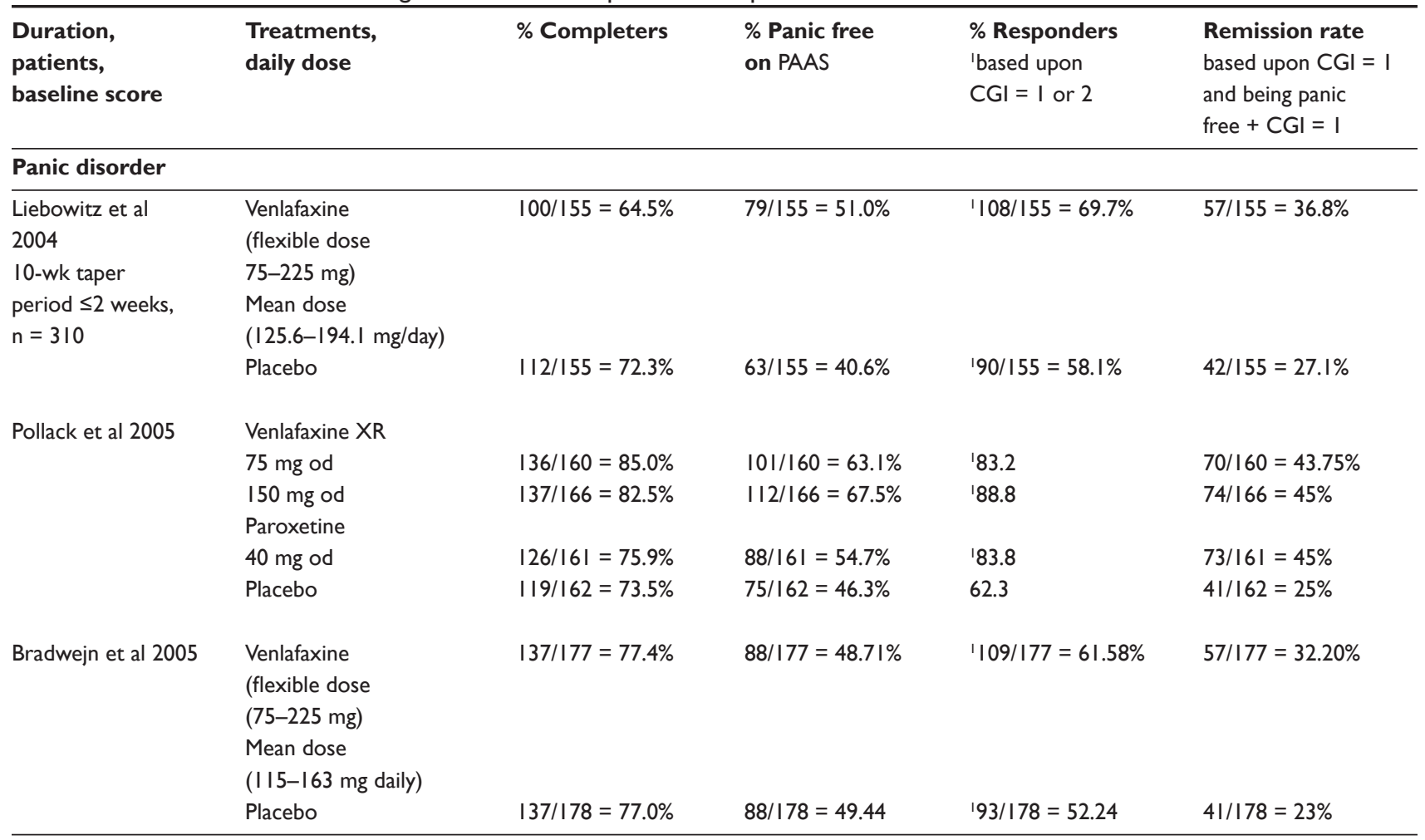

as noted on the PAAS (Panic and Anxiety Anticipatory Scale), change in the percentage of time subjects experience anticipatory anxiety, Phobia Scale (fear and Avoidance factors), and the Q-LES-Q (Quality of Life Enjoyment and Satisfaction Questionnaire). Pollack et al (2005) reported that all three treatment groups showed significant improvement in the primary and secondary outcome measures in relation to the placebo-treated group, but that in particular, the group treated with $225 \mathrm{mg}$ venlafaxine XR per day showed improvement in the percentage of patients who were panic free $(\mathrm{p} \leq 0.023)$ and a greater total score improvement in the total PDSS compared with the group receiving paroxetine at a dose of $40 \mathrm{mg}$ daily ( $\mathrm{s} \leq 0.033$ ). This difference, while significant, may represent an unfair choice of dosing for paroxetine, suggesting that a higher dose of paroxetine may have been more effective. As well, significant improvements with the venlafaxine XR- and paroxetine-treated groups showed a $75 \%$ response rate and roughly a $50 \%$ remission rate at completion of the study (Table 3 ).

In a comparison of quality of life and functionality with venlafaxine XR and paroxetine and placebo, Khandker et al (2005) reported specifically on a variety of secondary outcome measures of functional impairment including the
Sheehan Disability Scale and the Quality of Life Enjoyment and Satisfaction Questionnaire (Q-LES-Q). Impairment levels were assessed at baseline, and treatment-related improvement measured at FOT evaluation and at 12 weeks. Khandker et al (2005) reported that the group taking 225 $\mathrm{mg}$ /day of venlafaxine XR showed significant differences from pre-treatment baseline measures in nine of the ten domains of the Q-LES-Q ( $\mathrm{p} \leq 0.005$ ), the only domain not showing a significant difference being the School and Coursework domain. This differed from the group taking $75 \mathrm{mg}$ /day of venlafaxine XR, who showed significant changes from pre-treatment baseline measures in eight of the ten domains ( $p \leq 0.05$ ), with the only domains not showing difference from baseline being the School and Coursework domain and the Household Duties domain. Interestingly, the group receiving paroxetine at a dose of $40 \mathrm{mg}$ /day showed significant differences from pre-treatment baseline measures in all ten domains of the Q-LES-Q.

As for the results with the Sheehan Disability Scale, Khandker et al (2005) reported that significant changes were noted in all four domains of the SDS (work; social life and leisure activities; family life and home responsibilities; and work and social disability) with venlafaxine XR at $75 \mathrm{mg}$ /day 
( $\mathrm{p} \leq 0.01)$, venlafaxine XR at $225 \mathrm{mg} /$ day $(\mathrm{p} \leq 0.001)$, and paroxetine at $40 \mathrm{mg} /$ day $(\mathrm{p} \leq 0.05)$.

Ferguson et al (2005) recently undertook a multicenter, randomized, placebo-controlled, parallel group study of 313 patients, 18 years or older, suffering with panic disorder, who were enrolled initially in an open-label trial of venlafaxine $\mathrm{XR}$, with those who met criteria for "responder" $(\leq 1$ panic attack per week in the final 2 weeks prior to the end of the open-label phase and a CGI score of 1 or 2) being randomized to a 12-week placebo-controlled, parallel group comparison study. Outcome measures included the primary outcome measure of time to relapse, with secondary outcome measures of the PAAS (Panic and Anxiety Anticipatory Scale) including the percentage of patients who are panic-free and the PAAS panic frequency and the PDSS (Panic Disorder Severity Scale), CGI-S, Phobia Scale Fear Factor, Phobia Scale Avoidance Factor, Overall Phobia Scale, Hamilton Anxiety Scale, Montgomery Asberg Rating Scale (MADRS), Sheehan Disability Rating Scale (SDS), Quality of Life Enjoyment and Satisfaction Questionnaire (Q-LES-Q), Resource Utilization in Panic Disorder (RUPD). Ferguson et al (2005) reported that the 92 subjects randomized to the venlafaxine XR group showed a significantly lower relapse rate (22.5\%) compared with the relapse rate (50\%) in the 90 subjects randomized to the placebo group $(p<0.001)$. Statistical differences were noted between the two groups in the secondary outcome measures including number of panic attacks, PDSS anticipatory, psychic, somatic fear and avoidance subscales and the CGI-S, the SDS subscales of work, social life and leisure activities, family life and home responsibilities, global work and social disability scores ( $\mathrm{p}<0.001)$, and all but one of the Q-LES-Q subscales (school and course work).

Mallick et al (2004) reported on a recent pooled analysis of two short-term randomized placebo-controlled studies of venlafaxine XR (75 mg, $150 \mathrm{mg}$, and flexible dose), one of which included the paroxetine comparison group (Pollack et al 2005) during 10-12 weeks of treatment for panic disorder, and on a pooled analysis of four randomized, double-blind, placebocontrolled studies (two of which were also paroxetine controlled). Mallick et al (2003) reported that at baseline, score of the physical health activities subscale of the Q-LES-Q was 2.8 (the lowest of the Q-LES-Q subscales) and that changes in the subscale were substantially changed in both the venlafaxine groups compared with the placebo group.

In summary, while it may have been suggested that venlafaxine as an SNRI would not be an effective treatment for panic disorder, there are clear data showing that it is at least as effective as the SSRI paroxetine, As such, further and larger comparison trial and/or meta-analyses should be undertaken to examine whether there is any clear advantage of venlafaxine over the SSRIs in panic disorder.

\section{Safety and tolerability}

In large trials in patients with social anxiety disorder (SAD) or generalized anxiety disorder (GAD), the most common treatment-related adverse events were nausea, insomnia, anorexia, asthenia, dizziness, and sexual dysfunction (Greenberg et al 1999; Gelenberg et al 2000; Mallick et al 2002; Wyeth Laboratories 2003). Side-effects are similar to those seen in patients with depression and generally subside with continued treatment (Wyeth laboratories 2003, Mallick et al 2002).

Approximately $17 \%-18 \%$ of patients with SAD or GAD withdrew from venlafaxine treatment because of adverse events, compared with $5 \%-12 \%$ of placebo-treated patients (Wyeth Laboratories 2003). The most common adverse event leading to discontinuation and considered to be drug-related was nausea at $4 \%-8 \%$. Other events leading to discontinuation in $1 \%-3 \%$ of patients were asthenia, headache, dry mouth, dizziness, insomnia, somnolence, nervousness, sweating, and impotence in men.

In studies on panic disorder, the drop out rate because of adverse events on the venlafaxine XR was $9 \%-10 \%$ in the venlafaxine XR groups compared with $2 \%-5 \%$ in the placebo group vs $7 \%$ in the paroxetine group. No significant difference was noted in the groups in any of the three shortterm studies.

While electrocardiograph changes have been noted in some trials, generally they have been minor and of no clinical significance (Katz et al 2002). However, venlafaxine treatment has been associated with sustained increases in blood pressure in some patients $(0.5 \%-1.4 \%)$. Pooled analysis of 5 trials including 1839 patients with GAD treated with venlafaxine for 8 weeks reported a non-significant $0.6 \mathrm{mmHg}$ decrease in supine diastolic blood pressure in older patients (Katz et al 2002). Venlafaxine-treated patients in GAD and SAD studies experienced significantly higher mean changes in heart rate than placebo-treated patients (a mean increase of 3-5 beats per minute for venlafaxine and no change for placebo) (Wyeth Laboratories 2003). However, analysis of older patients with GAD showed no significant changes in heart rate (Smith et al 2002).

In patients with renal impairment or cirrhosis of the liver, the clearance of venlafaxine is decreased, and the elimination 
half-life is prolonged (Wyeth Laboratories 2003). This suggests that extra care must be taken to ensure the safety of venlafaxine in this population.

Significant weight gain can be an unwanted effect of many antidepressant drugs. However, venlafaxine XR has little effect on body weight, with anorexia and weight loss reported in a small percentage of patients (Wyeth Laboratories 2003).

Rare but important adverse events with venlafaxine have been reported, including hyponatremia and/or the syndrome of inappropriate antidiuretic hormone secretion (SIADH) and mydriasis (Mallick and Gao 2003). There have been reports of abnormal bleeding (ecchymosis) associated with venlafaxine treatment, but in these rare cases no causal relationship was ever established. Clinically relevant increases in serum cholesterol were recorded in $5.3 \%$ of venlafaxine patients treated for at least 3 months in placebo-controlled trials.

Antidepressant therapy has also been reported to cause a switch to mania or hypomania in patients with bipolar disorder. Since anxiety disorders are frequently comorbid with bipolar disorder, this is an important consideration. In anxiety trials, there have been no reports of venlafaxine XR-treated patients experiencing mania or hypomania and only a $0.5 \%$ incidence in major depressive disorder trials (Mallick and Gao 2003). Nonetheless, venlafaxine should be used with caution in patients with a history of mania (Mallick and Gao 2003).

\section{Drug interactions}

The primary metabolizing enzymes for venlafaxine are CYP2D6 and CYP3A4 and the potential for interaction exists with drugs that produce simultaneous inhibition of these two enzyme systems. Venlafaxine is either a weak inhibitor or does not inhibit other CYP enzymes (Wyeth Laboratories 2003). Venlafaxine appears to have a low potential to inhibit the metabolism of substrates for CYP2D6 such as imipramine, desipramine, and risperidone, and is unlikely to be involved in a pharmacokinetic interaction (Amchin et al 1999; Albers et al 2000; Wyeth Laboratories 2003). Minor but clinically relevant interactions have been reported between venlafaxine and lithium, diazepam, and haloperidol (Troy et al 1996; Benazzi 1997; Mekler and Woggon 1997; Kudo and Ishizaki 1999; Mallick and Gao 2003). Cimetidine should be co-administered with caution in patients with compromised hepatic metabolic function (Troy et al 1998; Mallick and Gao 2003). In addition, venlafaxine should be used cautiously in patients receiving indinavir, as significant decreases in serum levels of indinavir can result (Levin et al 2001; Mallick and Gao 2003).
As with most antidepressant drugs, a potential interaction with MAOIs does exist with venlafaxine $\mathrm{XR}$, and serious adverse reactions have been reported (Brubacher et al 1996; Gitlin 1997; Hodgman et al 1997; Mallick and Gao 2003). Venlafaxine XR should not be used be used in combination with an MAOI, or within at least 14 days of discontinuing treatment with an MAOI. Based on the half-life of venlafaxine, at least 7 days should be allowed after stopping venlafaxine before starting an MAOI.

\section{Conclusion}

Venlafaxine is a useful pharmacological choice for the treatment of anxiety disorders, including SAD, GAD, post traumatic stress disorder (PTSD), OCD, and most recently panic disorder. Its demonstrated short-term and long-term efficacy makes it an obvious choice as a first-line treatment in panic disorder. Anxiety disorders frequently occur with major depressive disorder, and other psychiatric and somatic conditions. With its demonstrated efficacy in major depressive disorder and low risk of serious adverse events, venlafaxine can be used confidently in patients with panic disorder and its depression and anxiety comorbidities. The benefits of venlafaxine in patients with eating disorders and somatic pain syndromes further suggest its potential utility in patients with multiple comorbid conditions.

\section{Disclosures}

Dr. Katzman has been a consultant for Wyeth, GlaxoSmithKline, Lundbeck, Pfizer, Eli Lilly, Solve, Janssen Ortho, Bristol-Myers Squibb, Astra Zeneca, and Genuine Health. He has also undertaken research with the same companies.

\section{Information resources Informative websites}

Anxiety Disorders Association of Canada www.anxietycanada.ca

Anxiety Disorders Association of America www.adaaa.org Self-help programs for patients with anxiety www.anxieties.com.

Wyeth Laboratories, makers of Effexor ${ }^{\circledR}$ (venlafaxine $\mathrm{HCl}$ ) http://www.wyeth.com/products/wpp_products/pharmaceutical.asp

\section{References}

Albers L, Reist C, Vu R, et al. 2000. Effect of venlafaxine on imipramine metabolism. Psychiatry Res, 96:235-43.

Amchin J, Zarycranski W, Taylor KP, et al. 1999. Effect of venlafaxine on the pharmacokinetics of risperidone. J Clin Pharmacol, 39:297-09. 
[APA] American Psychiatric Association. 1994. Diagnostic and Statistical Manual of Mental Disorders, 4th ed. Washington DC: APA.

[APA] American Psychiatric Association. 1998. Practice Guideline for the Treatment of Patients with Panic disorder. Washington, DC: APA

Ballenger J. 2001. Treatment of anxiety disorders to remission. The J Clin Psychiatry, 62(Suppl 12):5-9.

Ballenger JC, Wheadon DE, Steiner M, et al. 1998. Double-blind, fixeddose, placebo-controlled study of paroxetine in the treatment of panic disorder. Am J Psychiatry, 155:36-42.

Benazzi F. 1997. Urinary retention with venlafaxine-haloperidol combination. Pharmacopsychiatry, 30:27.

Black DW, Wesner R, Boweres W, et al. 1993. A comparison of fluvoxamine, cognitive therapy and placebo in the treatment of panic disorder. Arch Gen Psychiatry, 50:44-50.

Bradwejn J, Ahokas A, Stein DJ, et al. 2005. Venlafaxine extended release capsules in panic disorder. Br J Psychiatry, 187:352-9.

Brubacher J, Hoffman R, Lurin M. 1996. Serotonin syndrome from venlafaxine-tranylcypromine interaction. Vet Hum Toxicol, 38:358-61.

Canadian Anxiety Disorders Treatment Guidelines Initiative. 2006. Submitted to Canadian Psychiatric Journal.

Davidson J. 2003. Venlafaxine XR versus sertraline and placebo in the acute treatment of PTSD [abstract]. Presented at Anxiety Disorders Association of America, Toronto, Canada; March 27-30 2003.

DuPont R, DuPont C, Rice D. 2002. Economic costs of anxiety disorders. In Stein D, Hollander E (eds). Textbook of anxiety disorders. Washington, DC: American Psychiatric Publishing. p 475-83.

Feighner J. 1999. Mechanism of action of antidepressant medications. $J$ Clin Psychiatry, 60(Suppl 4):4-11.

Gelenberg A, Lydiard R, Rudolph R, et al. 2000. Efficacy of venlafaxine extended-release capsules in nondepressed outpatients with generalized anxiety disorder: A 6-month randomized controlled trial. JAMA, 283:3082-8.

Gitlin M. 1997. Venlafaxine, monoamine oxidase inhibitors, and the serotonin syndrome. J Clin Psychopharmacol, 17:66-7.

Greenberg P, Sisitsky T, Kessler R, et al. 1999. The economic burden of anxiety disorders in the 1990s. J Clin Psychiatry, 60:427-35.

Guidelines for the treatment of anxiety disorders in primary care. 2000. Toronto: Queen's Printer of Ontario.

Hodgman M, Martin T, Krenzelok E. 1997. Serotonin syndrome due to venlafaxine and maintenance tranylcypromine therapy. Hum Exp Toxicol, 16:14-17.

Hoehn-Saric R, McLeod DR, Hipsley PA. 1993. Effects of fluvoxamine on panic disorder. J Clin Psychopharmacol, 13:321-6.

Katz I, Reynolds C, Alexopoulos G, Hackett D. 2002. Venlafaxine ER as a treatment for generalized anxiety disorder in older adults: Pooled analysis of five randomized placebo-controlled clinical trials. J Am Geriatr Soc, $50: 18-25$.

Kessler R, McGonagle K, Zhao S, et al. 1994. Lifetime and 12-month prevalence of DSM-III-r psychiatric disorders in the United States. Results from the national comorbidity survey. Arch Gen Psychiatry, 51:8-19.

Khandker RK, Zhang HF. 2005. Assessing the effects of quality of life and functionality in long-term relapse prevention study of venlafaxine in panic disorder. Presented at the US psychiatric and mental health congress; Las Vegas, Nevada, November 7-10 2005.

Klerman GL, Weissman MM,Ouellette R, et al. 1991. Panic Attacks in the community. Social morbidity and health care utilization, 265:742-6.

Kudo S, Ishizaki T. 1999. Pharmacokinetics of haloperidol: An update. Clin Pharmacokinet, 37:435-56.

Leinonen E, Lepola U, Koponen H, et al. 2000. Citalopram controls phobic symptoms in patients with panic disorder: randomized controlled trial. J Psychiatry Neurosc, 25:24-32.

Lepola U, Arato M, Zhu Y, Austin C. 2003. Sertraline versus imipramine treatment of comorbid panic disorder and major depressive disorder. $J$ Clin Psychiatry, 64:654-62.
Lepola UM, Wade AG, Leinonen EV, et al. 1998. A controlled, prospective, 1-year trial of citalopram in the treatment of panic disorder. J Clin Psychiatry, 59:528-34.

Levin G, Nelson L, De Vane C, et al. 2001. A pharmacokinetic drug-drug interaction study of venlafaxine and indinavir. Psychopharmacol Bull, 35:62-71.

Liebowitz MR, Asnis G, Tzanis E, et al. 2004. Presented at the US Psychiatric and Mental Health Congress; San Diego, California, November $18-212004$

Londborg PD, Wolkow R, Smith WT, et al. 1998. Sertraline in the treatment of panic disorder. A multi-site, double-blind, placebo-controlled, fixed-dose investigation. Br J Psychiatry, 173: 54-60.

Lydiard RB, Brawman-Mintzer O. 1997. Panic disorder across the life span: a differential diagnostic approach to treatment resistance. Bull Menninger Clin, 61(2 Suppl A):A66-94.

Lydiard RB, Steiner M, Burnham D, et al. 1998. Efficacy studies of paroxetine in panic disorder. Psychopharmacol Bull, 34:175-82.

Mallick R, Gao B. 2003. Quality of life and functionality in panic disorder improve with treatment [abstract 798]. Presented at 156th APA Annual Meeting; San Francisco, CA, May 17-22 2003.

Mallick R, Mangano R, Shrivastava R. 2002. Improvement in functionality with treatment of generalized social anxiety disorder: Venlafaxine XR vs placebo [abstract p.3.061]. Eur Neuropsychopharmacol, 12(Suppl 3):S356-7(2).

Mallick R, Zhang HF, Gao B. 2004. Presented at the American Academy of Family Physicians/World Congress of Family Doctors; Orlando, Florida, October 13-17 2004.

Mekler G, Woggon B. 1997. A case of serotonin syndrome caused by venlafaxine and lithium. Pharmacopsychiatry, 30:272-3.

Michelson D, Allgulander C, Dantendorfer K, et al. 2001. Efficacy of usual antidepressant dosing regimens of fluoxetine in panic disorder: randomized, placebo-controlled trial. Br J Psychiatry, 179:514-8.

Michelson D, Lydiard RB, Pollack MH, et al. 1998. Outcome assessment and clinical improvement in panic disorder: evidence from a randomized controlled trial of fluoxetine and placebo. The Fluoxetine Panic Disorder Study Group. Amn J Psychiatry, 155:1570-7.

Michelson D, Pollack M, Lydiard RB, et al. 1999. Continuing treatment of panic disorder after acute response: randomized, placebo-controlled trial with fluoxetine. The Fluoxetine Panic Disorder Study Group. $\mathrm{Br}$ $J$ Psychiatry, 174:213-8.

Montgomery S, Sheehan D, Meoni P, et al. 2002. Characterization of the longitudinal course of improvement in generalized anxiety disorder during long-term treatment with venlafaxine XR. J Psychiatr Res, 36:209-17.

Moran JA, Brockington JA, Wise RA, et al. 2002. Dopamine uptake through the norepinephrine transporter in brain regions with low levels of the dopamine transporter: evidence from knock-out mouse lines. J Neurosci, 22:389-95.

Muth E, Haskins J, Moyer J, et al. 1986. Antidepressant biochemical profile of the novel bicyclic compound wy-45,030, an ethyl cyclohexanol derivative. Biochem Pharmacol, 35:4493-7.

Oehrberg S, Christiansen PE, Behnke K, et al. 1995. Paroxetine in the treatment of panic disorder. A randomized, double-blind, placebo-controlled study. Br J Psychiatry, 167:374-9.

Pohl RB, Wolkow RM, Clary CM, 1998. Sertraline in the treatment of panic disorder: a double-blind multicentre trial. Am J Psychiatry, 155:1189-95.

Pollack, M.H. 1999. Social Anxiety Disorder: Designing a pharmacologic treatment strategy. J Clin Psychiatry, 60(Suppl 9):20-6.

Pollack MH, Entsuah R, Tzanis E, et al. 2005. Short-term treatment of Panic Disorder: Venlafaxine XR or Paroxetine. Presented at the World Federation of Societies of Biological Psychiatry; Vienna, Austria, June 28-July 32005.

Pollack MH, Otto MW, Worthington JJ, et al. 1998. Sertraline in the treatment of panic disorder: A flexible-dose, multicenter trial. Arch Gen Psychiatry, 55:1010-16. 
Pollack MH, Rappaport MH, Clary CM, et al. 2000. Sertraline treatment in panic disorder: Response in patients at risk for poor outcome. J Clin Psychiatry, 61:922-6.

Pollack MH, Rapaport MH, Fayyad R, et al. 2002. Early improvement predicts endpoint remission status in sertraline and placebo treatments of panic disorder. J Psychiatr Res, 36:229-36.

Rapaport MH, Davidson JR. 1998. The efficacy of new pharmacological treatments for panic disorder: evaluating the trials. Psychopharmacol Bull, 34:167-8.

Rapaport MH, Wolkow R, Rubin A, et al. 2001. Sertraline treatment of panic disorder: results of a long-term study. Acta Psychiatr Scand, 104:289-98.

Rickels K, Pollack M, Sheehan D, et al. 2000. Efficacy of extended-release venlafaxine in nondepressed outpatients with generalized anxiety disorder. Am J Psychiatry, 157:968-74.

Shear MK, Brown TA, Barlow DH, et al. 1997. Multicenter collaborative panic disorder severity scale. Am J Psychiatry, 154:1571-5.
Shear MK, Maser JD. 1994. Standardized assessment for panic disorder research. A conference report. Arch Gen Psychiatry, 51:346-54.

Smith D, Dempster C, Glanville J, et al. 2002. Efficacy and tolerability of venlafaxine compared with selective serotonin reuptake inhibitors and other antidepressants: A meta-analysis. Br J Psychiatry, 180:396-404.

Troy S, Parker V, Hicks D, et al. 1996. Pharmacokinetic interaction between multiple-dose venlafaxine and single-dose lithium. J Clinl Pharmacol, 36:175-81.

Troy S, Rudolph R, Mayersohn M, et al. 1998. The influence of cimetidine on the disposition kinetics of the antidepressant venlafaxine. J Clinl Pharmacol, 38:467-74.

Wade AG, Lepola U, Koponen HJ, et al. 1997. The effect of citalopram in panic disorder. Br J Psychiatry, 170:549-53.

Wyeth Laboratories. 2003. Effexor XR (venlafaxine hydrochloride) product monograph. 
